Article

\title{
Experimental Investigation on Mechanism of Latent Heat Reduction of Sodium Acetate Trihydrate Phase Change Materials
}

\author{
Liu Wu ${ }^{1,2}$, Jianqiang $\mathrm{Li}^{2, *}$, Hui Wang ${ }^{2}$, Ying Zhang ${ }^{2}$, Shaowei Feng ${ }^{2}$, Yongchang Guo ${ }^{2}$, \\ Jianling Zhao ${ }^{1}$, Xixin Wang ${ }^{1, *}$ and Lijiang Guo ${ }^{2, *}$ \\ 1 School of Materials Science and Engineering, Hebei University of Technology, Tianjin 300130, China; \\ lwu18@ipe.ac.cn (L.W.); zhaojl@hebut.edu.cn (J.Z.) \\ 2 National Engineering Laboratory for Hydrometallurgical Cleaner Production Technology, Key Laboratory of \\ Green Process and Engineering, Institute of Process Engineering, Chinese Academy of Sciences, \\ Beijing 100190, China; wangh@ipe.ac.cn (H.W.); yingzhang@ipe.ac.cn (Y.Z.); swfeng@ipe.ac.cn (S.F.); \\ guoyongchang18@mails.ucas.ac.cn (Y.G.) \\ * Correspondence: jqli@ipe.ac.cn (J.L.); xixinwang@126.com (X.W.); 1.j.guo@hotmail.com (L.G.)
}

Received: 25 November 2019; Accepted: 23 January 2020; Published: 26 January 2020

\begin{abstract}
Sodium acetate trihydrate (SAT) phase change material (PCM) has been well known for thermal energy storage due to its high latent heat and resource abundance. However, SAT suffers from severe latent heat reduction after heating and cooling cycles. Although a few of previous researches showed the reduction could be effectively inhibited by using thickeners, the mechanisms of the reduction process and thickeners' inhibition have not been deeply explored till now. In this work, SAT modified by $5 \mathrm{wt}$ \% nucleating agent of disodium hydrogen phosphate dodecahydrate (SAT/5 wt.\% DSP) was prepared and 200 thermal cycles were carried out. The differential scanning calorimeter, Rheometer, X-ray diffractometry, and scanning electron microscope were used to investigate the extent of latent heat reduction, viscosity, phase composition and microstructure, respectively, and the infrared thermal imaging method was used to evaluate heat storage capacity. It was found that the latent heat of SAT $/ 5 \mathrm{wt}$ \% DSP dropped dramatically and the relative decrease in latent heat was measured to be $22.44 \%$. The lower layer of SAT $/ 5 \mathrm{wt}$. $\%$ DSP contained $24.1 \mathrm{wt} . \% \mathrm{CH}_{3} \mathrm{COONa}$, which was quantitatively consistent with the reduction extent. Furthermore, the phase change endothermic time of the lower layer was only $44.1 \%$ of that of the upper. SAT $/ 5 \mathrm{wt}$. $\%$ DSP was further modified by $3 \mathrm{wt}$. \% thickener of carboxymethyl cellulose (SAT $/ 5 \mathrm{wt} . \% \mathrm{DSP} / 3 \mathrm{wt} . \% \mathrm{CMC}$ ) and endured 200 thermal cycles. The extent of the latent heat reduction of SAT $/ 5 \mathrm{wt}$. $\%$ DSP $/ 3 \mathrm{wt} . \%$ CMC was only $9.29 \%$, and phase compositions were more homogeneous. The 3 wt. \% CMC increased viscosity by 14 times, which effectively prevented the Stokes sedimentation velocity of $\mathrm{CH}_{3} \mathrm{COONa}$ in melts and inhibited the final macroscopic phase separation.
\end{abstract}

Keywords: phase change materials; sodium acetate trihydrate; phase separation; latent heat reduction

\section{Introduction}

Phase change materials (PCMs) for storing and releasing energy represent promising energy storage media to solve the mismatch between energy supply and demand [1-6]. In recent years, it has been widely used in the field of thermal energy storage, such as industrial waste heat recovery $[7,8]$, building heating [9-12], as well as solar energy systems [13-15]. Inorganic salt hydrate PCMs are considered as promising candidates owing to their merits of high latent heat, non-flammability, constant phase change temperature, and low cost $[16,17]$. As a typical inorganic salt hydrate PCM, sodium acetate trihydrate $\left(\mathrm{SAT}, \mathrm{CH}_{3} \mathrm{COONa} \cdot 3 \mathrm{H}_{2} \mathrm{O}\right)$ possesses high latent heat over $250 \mathrm{~kJ} / \mathrm{kg}$ compared 
with other hydrated salt PCMs and a phase change temperature of $58^{\circ} \mathrm{C}$, which offers great potential applications in the field of thermal energy storage [18-20].

Unfortunately, SAT suffers from large supercooling, which results in unpredictable crystallization that prevents stored heat from being released at phase change temperature during the cooling process [21,22]. Hence, considerable efforts have been made to overcome this shortcoming in recent years. Hu et al. [23] used AlN (aluminium nitride) nanoparticles as nucleating agent of SAT. The supercooling degree of SAT could be reduced to $0-2.4^{\circ} \mathrm{C}$ by adding $3-5 \mathrm{wt} . \%$ AlN nanoparticles. Mao et al. [24] investigated the effect of several nucleating agents on the supercooling of SAT. The results indicated that the minimum supercooling degree was $1.5^{\circ} \mathrm{C}$ when the addition amount of disodium hydrogen phosphate dodecahydrate (DSP) was $6 \mathrm{wt} . \%$ in SAT. Similarly, silver nanoparticles [25], nano-copper [26] and iron oxide nanoparticles $\left(\alpha-\mathrm{Fe}_{2} \mathrm{O}_{3}\right)$ [27] were used as nucleating agents to reduce the supercooling of SAT by researchers. Among which, DSP is an ideal nucleating agent considering the cost of the large-scale practical application of SAT compared with nanoparticles nucleating agents. Moreover, severe phase separation still occurs in SAT when the supercooling is lower [28]. Cabeza et al. [29] showed that cellulose was the appropriate thickener compared with starch and bentonite. The effect of thickeners including super-absorbent polymers, polyvinyl alcohol and carboxymethyl cellulose (CMC) on SAT was reported by Ryu et al. [30]. The phase separation of SAT was successfully inhibited by thickening with CMC. Furthermore, Dannemand et al. [31] discovered that the latent heat reduction of SAT composite PCMs could be effectively inhibited by using CMC as a thickener, and latent heat was consistently around $205 \mathrm{~kJ} / \mathrm{kg}$ over the six test cycles. However, thickeners (such as $\mathrm{CMC}$ ) are used to inhibit the phase separation of hydrated salt PCMs, but the current thickeners still cannot fundamentally solve the latent heat reduction of hydrated salts. Solving the latent heat reduction of hydrated salt PCMs in practical applications is still a challenging research direction.

In this work, the latent heat reduction process of SAT was analyzed during 200 heating and cooling cycles. Importantly, the mechanism of the thickener inhibiting latent heat reduction was analyzed. A small amount of CMC increased the viscosity of solution, which prevented effectively the Stokes sedimentation velocity of $\mathrm{CH}_{3} \mathrm{COONa}$ in melts and inhibited the final macroscopic phase separation. This study provides theoretical guidance for latent heat reduction studies of SAT and other hydrated salts in practical applications.

\section{Materials and Methods}

\subsection{Materials}

SAT $\left(\mathrm{CH}_{3} \mathrm{COONa} \cdot 3 \mathrm{H}_{2} \mathrm{O}\right)$, DSP $\left(\mathrm{Na}_{2} \mathrm{HPO}_{4} \cdot 12 \mathrm{H}_{2} \mathrm{O}\right)$ and $\mathrm{CMC}$ (carboxymethyl cellulose, analytical reagent grade, purity $>99 \%$ ) were purchased from Sinopharm Chemical Reagent Co., Ltd. (Beijing, China).

\subsection{Preparation of SAT Composite PCMs}

CMC and DSP were used as thickener and nucleating agent to restrain phase separation and reduce supercooling, respectively. The composition of SAT/DSP/CMC (SAT modified by DSP and $\mathrm{CMC}$ ) is listed in Table 1. It was reported that when the addition amount of CMC is $3 \mathrm{wt} . \%$, the phase separation of SAT was effectively inhibited, and the phase change performance was optimal [24]. Every sample was thoroughly mixed by magnetic stirring in a 150-mL beaker in a water bath with a constant temperature of $80{ }^{\circ} \mathrm{C}$, and then transferred to a $50 \mathrm{~mL}$ centrifuge tube with a cover, avoiding water evaporation. 
Table 1. Samples composition of SAT/DSP/CMC.

\begin{tabular}{ccccc}
\hline Samples & SAT (g) & DSP (g) & CMC (g) & $\begin{array}{c}\text { The mass ratio of } \\
\text { SAT:DSP:CMC }\end{array}$ \\
\hline 1 & 50 & 0.5 & 0 & $1: 0.01: 0$ \\
2 & 50 & 1.5 & 0 & $1: 0.03: 0$ \\
3 & 50 & 2.5 & 0 & $1: 0.05: 0$ \\
4 & 50 & 3.5 & 0 & $1: 0.07: 0$ \\
5 & 50 & 5.0 & 0 & $1: 0.1: 0$ \\
6 & 50 & 2.5 & 1.5 & $1: 0.05: 0.03$ \\
\hline
\end{tabular}

\subsection{Characterization}

The viscosity (liquid state) was measured by Rheometer (DHR-2, TA Instruments, New Castle, DE, USA) at $80^{\circ} \mathrm{C}$. The latent heat was measured using the differential scanning calorimeter (DSC, Mettler-Toledo, Stockholm, Sweden), setting temperature from 25 to $90^{\circ} \mathrm{C}$ with a heating/cooling rate of $10^{\circ} \mathrm{C} / \mathrm{min}$ under $\mathrm{N}_{2}$ at a flow rate of $50 \mathrm{~mL} / \mathrm{min}$. The component was analyzed by $\mathrm{X}$-ray diffractometry (XRD, Smartlab, Rigaku Corporation, Tokyo, Japan). The morphology of the sample was observed by an environmental scanning electron microscope (ESEM, Quanta Feg 250, FEI Corporation, Hillsboro, OR, USA). The temperature of the sample was recorded using an infrared thermal camera (226, Fotric, Allen, TX, USA).

\subsection{Supercooling Determination}

The supercooling degree $\Delta \mathrm{T}$ of the PCM can be calculated by the following formula [12]:

$$
\Delta \mathrm{T}=\mathrm{T}_{\mathrm{m}}-\mathrm{T}_{\mathrm{s}}
$$

where $T_{m}$ is the melting temperature and $T_{s}$ represents the solidification temperature. The purpose of this work is to study the reduction of latent heat of SAT during practical application, so DSP was used to reduce the supercooling of SAT. The cooling curve method was used to determine the supercooling degree of SAT composite PCMs. The as-prepared samples in the $50 \mathrm{~mL}$ centrifuge tubes were melted in a water bath with a constant temperature of $80^{\circ} \mathrm{C}$, and then cooled naturally at room temperature. Further, the temperatures of samples were recorded once a second by multichannel temperature recorder. Every sample was tested three times.

\subsection{Heat Storage Capacity Determination}

The heat storage capacity was qualitatively assessed by comparing the phase change time of samples under the same heating condition. Infrared thermal imaging method was used to observe the temperature changes of sample in heating and cooling process. The samples were pressed into wafers with the diameter of $2 \mathrm{~cm}$ and the quantity of $1 \mathrm{~g}$, and then put in a glass dish without covering, floating above the oil bath of $80^{\circ} \mathrm{C}$. The temperatures of samples were recorded using an infrared thermal camera. The equipment is shown in Figure 1. 


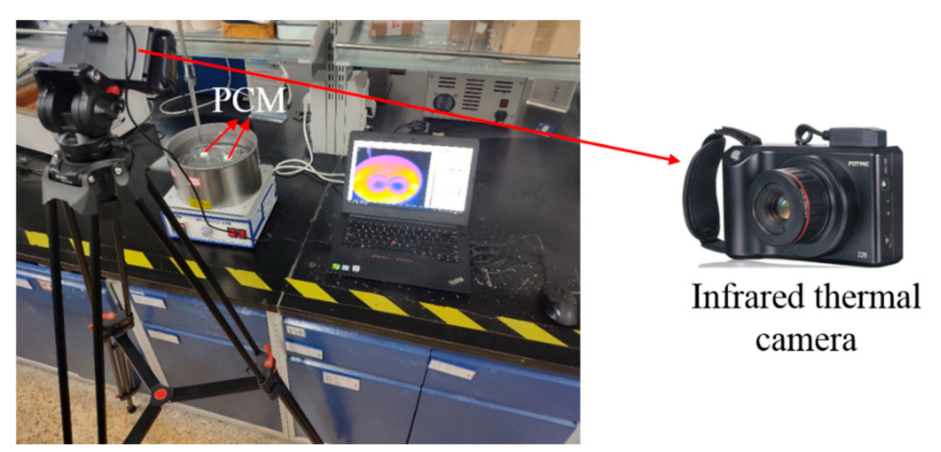

Figure 1. The equipment of heat storage capacity determination.

\subsection{Thermal Stability Determination}

The thermal stabilities of SAT/5 wt.\% DSP and SAT/5 wt.\% DSP/3 wt.\% CMC were determined by comparing the latent heat changes before and after heating and cooling cycles. Four 1-g samples of SAT $/ 5$ wt.\% DSP were placed in $1.5 \mathrm{~mL}$ centrifuge tubes. Then these centrifuge tubes were immersed in a water bath at the constant temperature of $80^{\circ} \mathrm{C}$. When the temperatures of samples didn't change, they were quickly placed into the $20^{\circ} \mathrm{C}$ water bath. Four samples were cycled 40, 80, 150, and 200 times as described above. Then every resulting sample was taken out of the centrifuge tubes, and ground uniformly, and then a few milligrams of powder sample were used for DSC testing. Same thermal stability test process of SAT/5 wt.\% DSP/3 wt.\% CMC was carried out. Every sample was tested five times. The error of the DSC test result is no more than $10 \mathrm{~J} / \mathrm{g}$.

\section{Results and Discussion}

\subsection{Influence of DSP on Supercooling}

Cooling curves and supercooling degrees of SAT modified by different contents of DSP are illustrated in Figure 2. It can be observed that the SAT/1 wt.\% DSP (SAT with 1 wt.\% DSP) doesn't solidify, while the SAT with $3 \mathrm{wt}$.\% to $10 \mathrm{wt}$ \% DSP solidified with some extent of supercooling. When the content of DSP is $5 \mathrm{wt} . \%$, the supercooling degree is $2.9^{\circ} \mathrm{C}$, which is the lowest as shown in Figure $2 b$.

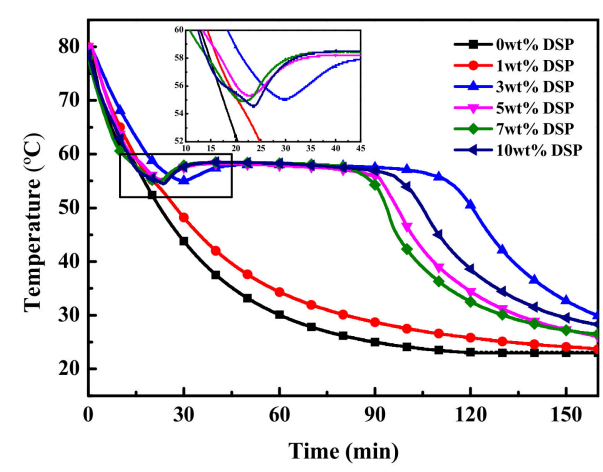

(a)

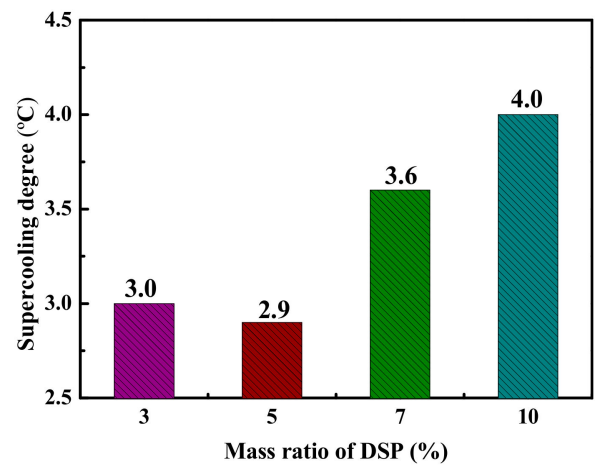

(b)

Figure 2. (a) Cooling curves and (b) supercooling degrees of SAT modified by different contents of DSP.

\subsection{The Analysis of Latent Heat Reduction}

The 200 heating and cooling cycles of SAT/5 wt.\% DSP were carried out. The DSC measurements of SAT/5 wt.\% DSP in different cycles are shown in Figure 3, and a concave peak is observed in each DSC melting curve. As the number of cycles increases, the area of the peak decreases. This indicates 
that the latent heat of SAT/5 wt.\% DSP is decreasing during 200 heating and cooling cycles. The extent of latent heat reduction was calculated by the following formula [32]:

$$
\alpha=\frac{\left(\Delta \mathrm{H}_{1}-\Delta \mathrm{H}_{2}\right)}{\Delta \mathrm{H}_{1}} \times 100 \%
$$

where $\alpha$ is the extent of latent heat reduction, $\Delta \mathrm{H}_{1}$ represents the latent heat of the initial sample, and $\Delta \mathrm{H}_{2}$ is the latent heat of sample after different thermal cycles.

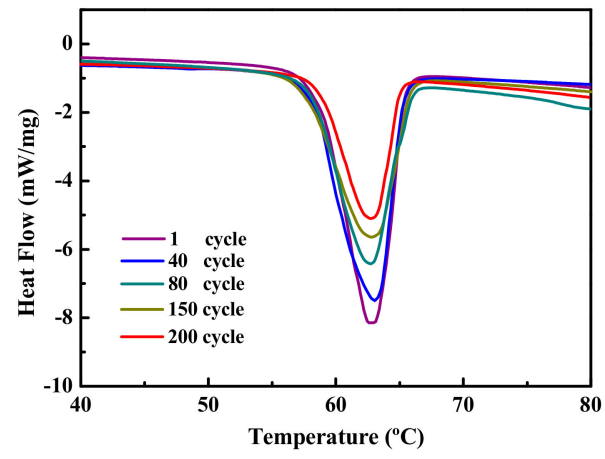

(a)

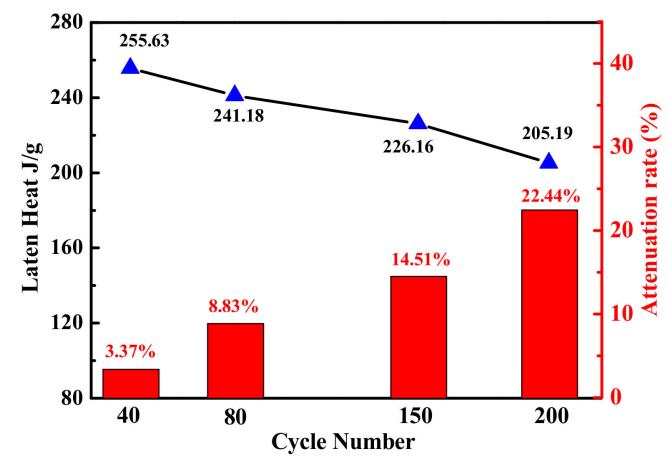

(b)

Figure 3. (a) DSC melting curves, (b) latent heat change curve and reduction extent of SAT/5 wt.\% DSP at different cycles.

The five DSC test results of the SAT $/ 5 \mathrm{wt} . \%$ DSP are shown in Table 2 . The experimental results are the mean values of five test results. The standard deviations of the latent heat for 40, 80, 150, 200 cycles are calculated respectively as 4.72, 5.03, 4.58, 4.52. After 200 heating and cooling cycles, the latent heat of SAT/5 wt. \% DSP drops to $205.19 \mathrm{~J} / \mathrm{g}$ as shown in Figure $3 \mathrm{~b}$. The extent of latent heat reduction of SAT $/ 5$ wt. $\%$ DSP increases from $3.37 \%$ in 40 cycles to $22.44 \%$ in 200 cycles.

Table 2. The five DSC test results of the SAT $/ 5$ wt. \% DSP.

\begin{tabular}{ccccc}
\hline Test Frequency & 40 Cycle $(\mathbf{J} / \mathbf{g})$ & $\mathbf{8 0}$ Cycle $(\mathbf{J} / \mathbf{g})$ & $\mathbf{1 5 0}$ Cycle $(\mathbf{J} / \mathbf{g})$ & 200 Cycle $(\mathbf{J} / \mathbf{g})$ \\
\hline 1 & 251.84 & 236.15 & 220.73 & 199.65 \\
2 & 253.67 & 248.23 & 233.59 & 202.37 \\
3 & 262.98 & 239.82 & 222.64 & 203.28 \\
4 & 259.15 & 245.83 & 228.76 & 208.43 \\
5 & 250.51 & 235.87 & 225.08 & 212.22 \\
\hline
\end{tabular}

Figure $4 \mathrm{a}$ is the $52.5 \mathrm{~g}$ original sample of SAT $/ 5 \mathrm{wt} . \%$ DSP and Figure $4 \mathrm{~b}$ shows the sample cycled 200 times. The uncrystallized liquid phase was observed in SAT/5 wt.\% DSP after 200 heating and cooling cycles in Figure 4b. The 200 cycled sample in the $50 \mathrm{~mL}$ centrifuge tube was cut vertically from the top to the bottom of the centrifuge tube, and the profile is shown in Figure $4 \mathrm{~d}$. The morphology at a bottom height of $3 \mathrm{~cm}$ of SAT/5 wt.\% DSP is illustrated in Figure 4c. Different morphologies are observed on both sides of the interface, which indicates that the components on both sides of the interface are different. It should be pointed out that phase separation occurs in SAT/5 wt. $\%$ DSP after 200 heating and cooling cycles.

Furthermore, the SAT/5 wt.\% DSP was cut horizontally at the interface and divided into two layers: the upper and lower samples. The crystalline phases of upper and lower samples were analyzed by XRD as shown in Figure 5a. SAT exhibits strong peaks at $11.3^{\circ}, 16.8^{\circ}$, and $29.58^{\circ}$ (2 Theta) observing in the XRD pattern of the upper sample. Furthermore, $\mathrm{Na}_{2} \mathrm{HPO}_{4} \cdot 2 \mathrm{H}_{2} \mathrm{O}$ and $\mathrm{Na}_{2} \mathrm{HPO}_{4}$ show weak peaks, which is caused by the decomposition of DSP [33,34]. The $\mathrm{CH}_{3} \mathrm{COONa}$ is observed at $8.83^{\circ}$ and $23.08^{\circ}$ in the XRD pattern of the lower sample, which confirms that phase separation has occurred in SAT/5 
wt.\% DSP. Figure $5 \mathrm{~b}$ shows the semi-quantitative analysis results of the upper and lower samples by $\mathrm{k}$ value method. It can be seen from the Figure $5 b$ that the component of lower sample is mainly SAT with a mass ratio of $53.2 \%$, and the $24.1 \mathrm{wt}$ \% of $\mathrm{CH}_{3} \mathrm{COONa}$ of lower sample is much higher than 2.7 wt.\% of the upper sample. As presented in Figure 5c, SAT melts to form saturated sodium acetate solution at $80^{\circ} \mathrm{C}$ [13]. The saturated sodium acetate solution and $\mathrm{CH}_{3} \mathrm{COONa}$ have densities of 1280 $\mathrm{kg} / \mathrm{m}^{3}$ and $1517 \mathrm{~kg} / \mathrm{m}^{3}$ [13]. Therefore, $\mathrm{CH}_{3} \mathrm{COONa}$ sinks to the bottom owing to higher density when $\mathrm{SAT} / 5 \mathrm{wt}$ \% DSP is in a molten state, leading to aggregate at the lower layer and the formation of an interface between the sediment and liquid phase.
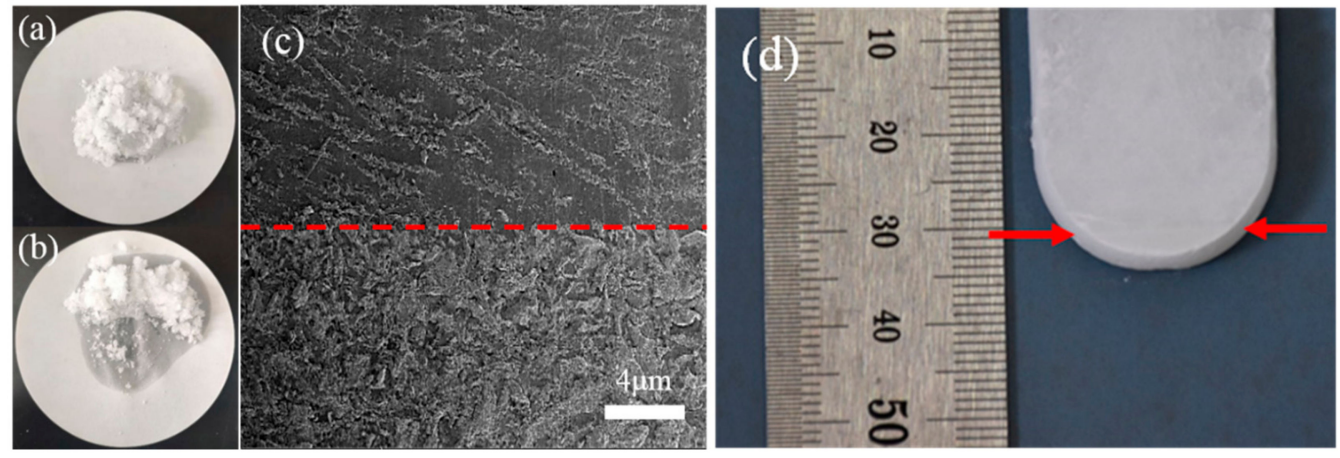

Figure 4. (a) The original sample of SAT/5wt\%DSP and (b) the sample cycled 200 times; (c) SEM image of lower sample of SAT $/ 5 \mathrm{wt} \% \mathrm{DSP}$; (d) the profile of SAT $/ 5 \mathrm{wt} \% \mathrm{DSP}$.

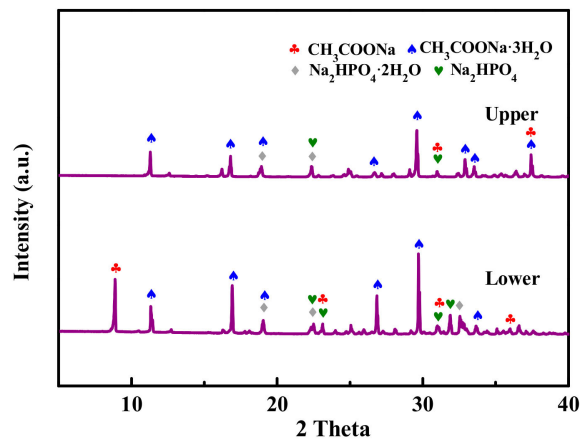

(a)

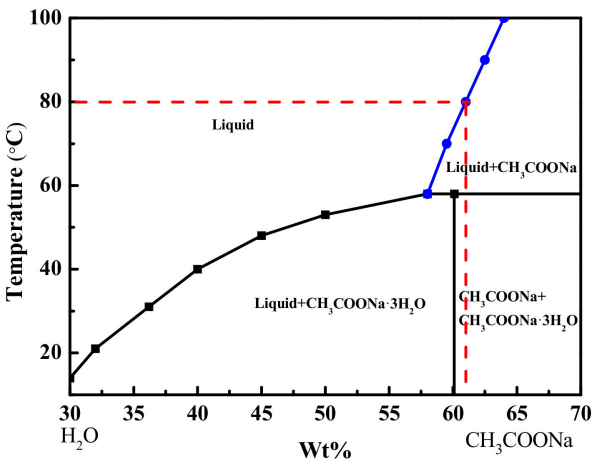

(c)

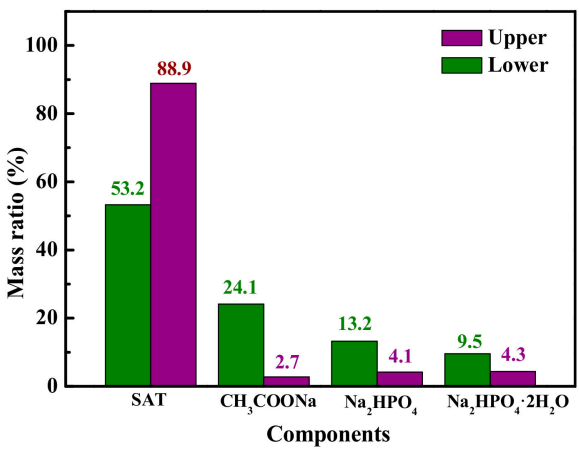

(b)

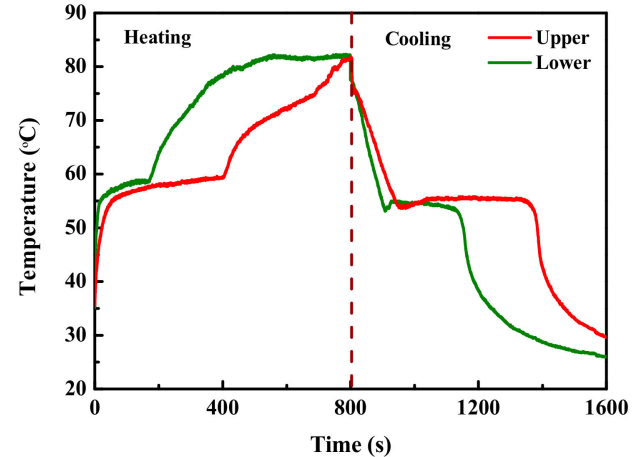

(d)

Figure 5. (a) XRD patterns and (b) semi-quantitative analyses of upper and lower samples of SAT/5 wt.\% DSP; (c) Phase diagram of sodium acetate-water system [13]; (d) Temperature-time curves of upper and lower samples of SAT/5 wt.\% DSP.

The temperature-time curves (Figure 5d) and temperature-distribution images (Figure 6) of upper and lower samples of SAT/5 wt.\% DSP were obtained using an infrared thermal camera. As shown in Figure $5 d$, the temperature-time curves of the upper and lower samples have two temperature plateaus 
around $55-58{ }^{\circ} \mathrm{C}$, which represent thermal energy storage and release in the form of latent heat. The phase change endothermic time of the lower sample is only 150s, but 340s of that for the upper sample. The shorter phase change endothermic time of the lower sample is due to the fact that it only contains $53.2 \mathrm{wt}$ \% SAT. It is worth noting that the phase change of lower sample firstly occurs when the heating time is $25 \mathrm{~s}$, because its sensible heat is lower than that of the upper sample. When the heating time is 350s, the temperature of the upper sample is $58^{\circ} \mathrm{C}$ indicating that the phase change is still under way, while the lower sample has ended the phase change process and its temperature reaches to $77^{\circ} \mathrm{C}$. It can be inferred that the latent heat of SAT/5 wt.\% DSP decreases by $22.44 \%$, which is because 24.1 wt. $\% \mathrm{CH}_{3} \mathrm{COONa}$ without heat storage capacity aggregates at the lower layer.

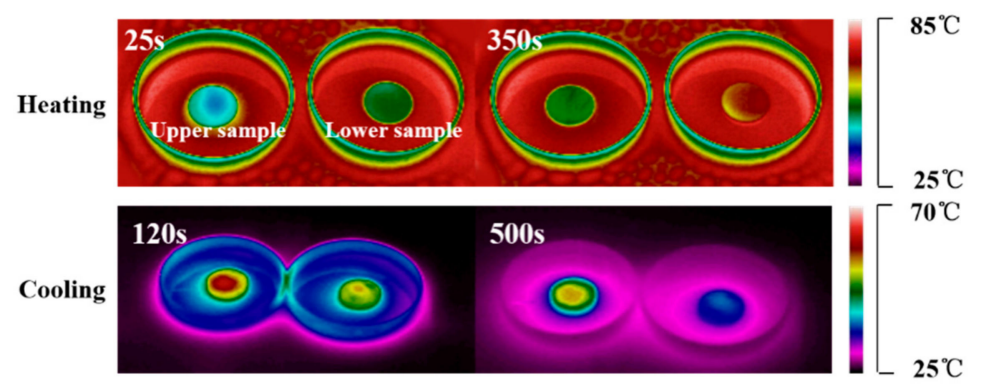

Figure 6. Infrared ray (IR) images of upper and lower samples of SAT/5 wt.\% DSP during heating and cooling process.

\subsection{The Analysis of Inhibiting Latent Heat Reduction}

The DSC measurements of SAT/5 wt.\% DSP/3 wt.\% CMC during different heating and cooling cycles was shown in Figure 7a. The areas of concave peak decrease with the increase of the cycle number of SAT/5 wt. \% DSP/3 wt. \% CMC. The extent of latent heat reduction of SAT $/ 5$ wt. $\%$ DSP $/ 3$ wt. $\%$ CMC was calculated by formula (2) as presented in Figure $7 \mathrm{~b}$. The $3 \mathrm{wt} . \% \mathrm{CMC}$ reduces the extent of latent heat reduction of SAT/5 wt.\% DSP from $22.44 \%$ to $9.29 \%$. The SAT $/ 5$ wt. $\%$ DSP $/ 3$ wt. $\%$ CMC was divided into two layers (the upper and lower samples) in the same way as that of SAT/5 wt. $\%$ DSP. Figure 7c represents the XRD patterns of upper and lower sample of SAT/5 wt.\% DSP/3 wt.\% $\mathrm{CMC}$, and the characteristic peaks of SAT at $11.3^{\circ}, 16.8^{\circ}$, and $29.58^{\circ}$ (2 Theta) are observed in the XRD patterns of the upper and lower samples. The $\mathrm{CH}_{3} \mathrm{COONa}$ shows weak peaks at $24.73^{\circ}, 26.86^{\circ}, 34.41^{\circ}$, and $35.62^{\circ}$ ( 2 Theta) in the XRD patterns of the upper and lower samples. The results indicate that there is slight phase separation in SAT/5 wt.\% DSP $/ 3 \mathrm{wt} . \% \mathrm{CMC}$.

The temperature-time curves and temperature-distribution images of upper and lower samples of SAT/5 wt.\% DSP/3 wt.\% CMC are shown in Figures 7d and 8, respectively. As illustrated in Figure 7d, there are two temperature plateaus with only slight changes on the temperature-time curves of upper and lower samples of SAT $/ 5 \mathrm{wt} . \% \mathrm{DSP} / 3 \mathrm{wt} . \% \mathrm{CMC}$. This indicates that the phase change endothermic time of the lower sample of SAT/5 wt.\% DSP $/ 3$ wt.\% CMC is consistent with that of the upper, which is attributed to the uniform composition of the upper and lower samples. It can be concluded that 3 wt.\% CMC can effectively slow down the extent of latent heat reduction of SAT by inhibiting the phase separation. 


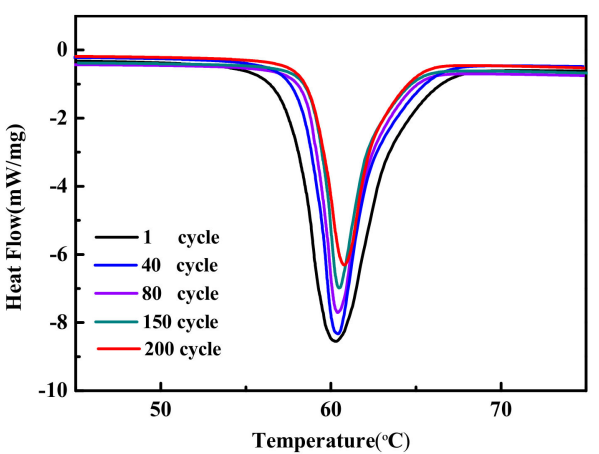

(a)

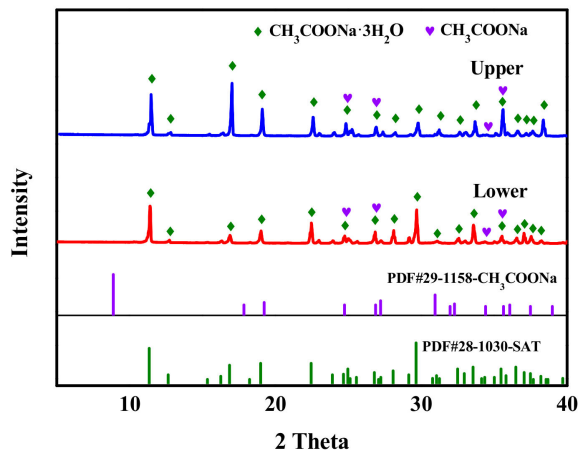

(c)

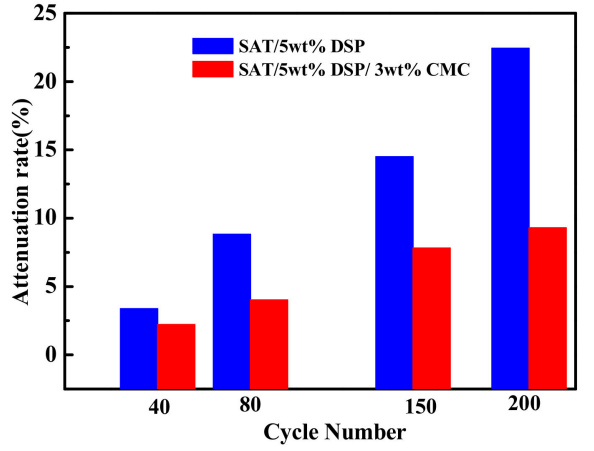

(b)

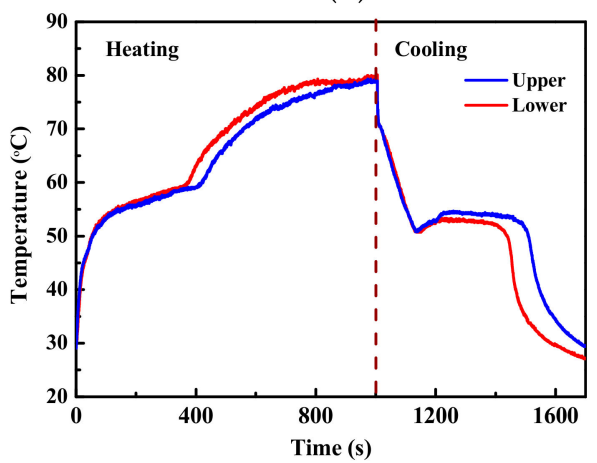

(d)

Figure 7. (a) DSC melting curves of SAT $/ 5$ wt. $\%$ DSP $/ 3$ wt. $\%$ CMC and (b) the extent of latent heat reduction of SAT $/ 5$ wt. $\%$ DSP and SAT $/ 5$ wt. $\%$ DSP $/ 3$ wt. $\%$ CMC at different cycles; (c) XRD patterns and (d) temperature-time curves of upper and lower samples of SAT $/ 5 \mathrm{wt} . \% \mathrm{DSP} / 3 \mathrm{wt} . \% \mathrm{CMC}$.

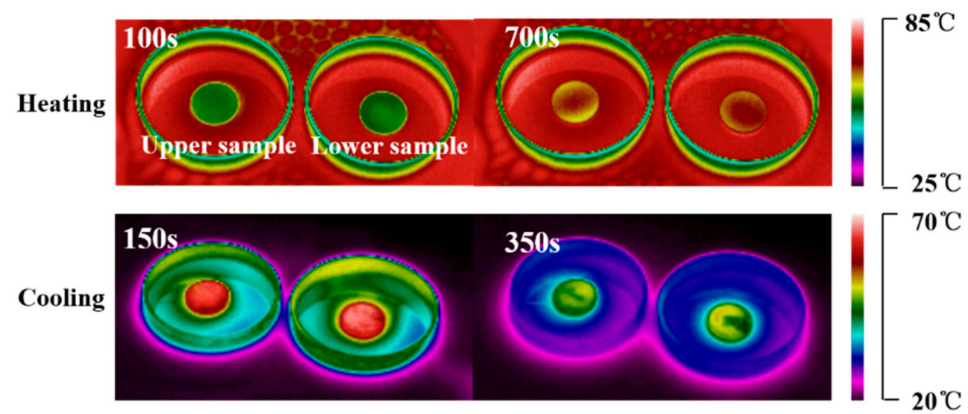

Figure 8. IR images of upper and lower samples of SAT $/ 5 \mathrm{wt} . \% \mathrm{DSP} / 3 \mathrm{wt} . \% \mathrm{CMC}$ during heating and cooling process.

To further investigate the mechanism of thickeners' inhibition, the viscosity of the sample was measured. The viscosity curves of SAT $/ 5$ wt. $\%$ DSP and SAT $/ 5$ wt. \% DSP $/ 3$ wt. \% CMC after 200 heating and cooling cycles at $80{ }^{\circ} \mathrm{C}$ are shown in Figure 9 . The viscosities of SAT $/ 5 \mathrm{wt} . \%$ DSP and SAT $/ 5 \mathrm{wt} . \%$ DSP/3 wt. \% CMC are $6.02 \mathrm{mPa} \cdot \mathrm{s}$ and $88.50 \mathrm{mPa} \cdot \mathrm{s}$, respectively. The relationship between the Stokes settling velocity of anhydrous salt and viscosity of solution can be evaluated by Stokes law [35]:

$$
\mathrm{V}=\frac{\mathrm{D}\left(\rho_{\mathrm{p}}-\rho_{\mathrm{b}}\right) \mathrm{r}^{2}}{\eta}
$$

where $\mathrm{V}$ is the Stokes settling velocity of anhydrous salt, $\mathrm{D}$ is constant, $\rho_{\mathrm{p}}$ and $\rho_{\mathrm{b}}$ represent anhydrous salt density and solution density, $\mathrm{r}$ is radius of anhydrous salt, and $\eta$ is the viscosity of solution. 


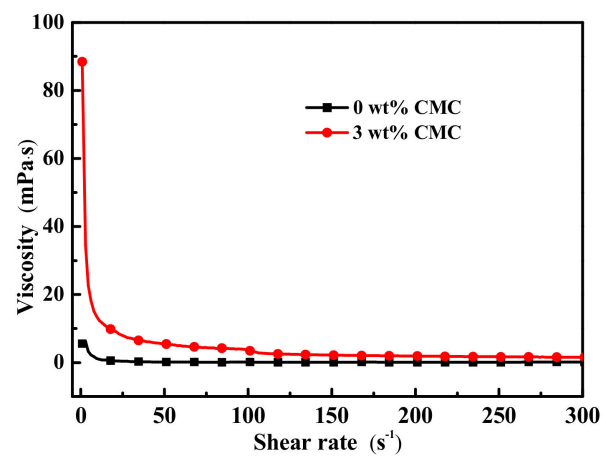

Figure 9. Viscosity curves of SAT $/ 5$ wt. $\%$ DSP and SAT $/ 5$ wt. $\%$ DSP $/ 3$ wt. $\% \mathrm{CMC}$ at $80^{\circ} \mathrm{C}$.

According to the Stokes law, the Stokes settling velocity of anhydrous salt is inversely proportional to the viscosity of solution. Provided that $\mathrm{r}$ of $\mathrm{CH}_{3} \mathrm{COONa}$ in SAT $/ 5 \mathrm{wt} . \%$ DSP and SAT $/ 5 \mathrm{wt.} \% \mathrm{DSP} / 3$ wt. $\%$ CMC does not change. The Stokes settling velocity of $\mathrm{CH}_{3} \mathrm{COONa}$ in SAT $/ 5 \mathrm{wt} . \% \mathrm{DSP} / 3 \mathrm{wt} . \%$ CMC is $0.0027 \mathrm{r}^{2} \mathrm{~m} / \mathrm{s}$, which is 8.07 times lower than $0.0218 \mathrm{r}^{2} \mathrm{~m} / \mathrm{s}$ of SAT $/ 5 \mathrm{wt} . \%$ DSP. During the heating process of SAT $/ 5 \mathrm{wt}$. $\%$ DSP, $\mathrm{CH}_{3} \mathrm{COONa}$ rapidly settles to the bottom on account of low viscosity and forms a solid-liquid interface, which prevents the combination of $\mathrm{CH}_{3} \mathrm{COONa}$ below the interface with the liquid phase in cooling process. When SAT/5 wt.\% DSP is cooling, the $\mathrm{CH}_{3} \mathrm{COONa}$ under the interface does not undergo phase change. During certain heating and cooling cycles, as the heating and cooling cycle increases, more and more $\mathrm{CH}_{3} \mathrm{COONa}$ without heat storage capacity will settle down, resulting in the reduction of latent heat. Inversely, the settling velocity of $\mathrm{CH}_{3} \mathrm{COONa}$ is significantly reduced due to the higher viscosity during the heating process of SAT $/ 5 \mathrm{wt} . \% \mathrm{DSP} / 3 \mathrm{wt} . \% \mathrm{CMC}$, so that a large proportion of $\mathrm{CH}_{3} \mathrm{COONa}$ can't aggregate at the lower layer and continue to phase change in cooling process. Thus, its latent heat is relative reduced.

\section{Conclusions}

The mechanisms of SAT latent heat reduction process and the thickeners' inhibition were investigated. SAT modified by $5 \mathrm{wt} . \%$ disodium hydrogen phosphate dodecahydrate (SAT $/ 5 \mathrm{wt} . \%$ DSP) and further modified by $3 \mathrm{wt} . \%$ carboxymethyl cellulose (SAT $/ 5 \mathrm{wt} . \% \mathrm{DSP} / 3 \mathrm{wt} . \% \mathrm{CMC}$ ) were prepared and 200 heating and cooling cycles were carried out. For the SAT $/ 5 \mathrm{wt} . \%$ DSP, the results showed that $24.1 \mathrm{wt} . \% \mathrm{CH}_{3} \mathrm{COONa}$ aggregated at the lower layer of SAT $/ 5 \mathrm{wt} . \%$ DSP, forming a solid-liquid interface and preventing the phase change of $\mathrm{CH}_{3} \mathrm{COONa}$ under the interface during the cooling process. As a result, the latent heat of SAT $/ 5 \mathrm{wt} . \%$ DSP decreased with the increase of the heating and cooling cycles. In contrast, the phase composition of SAT $/ 5 \mathrm{wt} . \% \mathrm{DSP} / 3 \mathrm{wt} . \% \mathrm{CMC}$ was more homogeneous. The viscosity of SAT $/ 5 \mathrm{wt} . \% \mathrm{DSP} / 3 \mathrm{wt} . \%$ CMC was 14 times higher than that of $\mathrm{SAT} / 5 \mathrm{wt} . \% \mathrm{DSP}$, and the settling velocity of $\mathrm{CH}_{3} \mathrm{COONa}$ in SAT $/ 5 \mathrm{wt} . \% \mathrm{DSP} / 3 \mathrm{wt} . \% \mathrm{CMC}$ reduced by 8.07 times. Therefore, a large proportion of $\mathrm{CH}_{3} \mathrm{COONa}$ interacted with liquid phase during cooling process, which slow down the extent of latent heat reduction.

Author Contributions: Conceptualization, L.W. and J.L.; methodology, L.W., H.W. and Y.Z.; validation, J.L.; formal analysis, L.W., H.W. and Y.Z.; investigation, L.W., Y.G. and J.Z.; data curation, L.W.; writing-original draft preparation, L.W.; writing-review and editing, L.W., Y.Z., L.G. and S.F.; supervision, J.L. and X.W.; project administration, J.L., X.W. and L.G.; funding acquisition, J.L. All authors have read and agreed to the published version of the manuscript.

Funding: This research was funded by the National Key Research and Development Program of China (2016YFC0700905 and 2017YFC0703200) and Transformational Technologies for Clean Energy and Demonstration Strategic Priority Research Program of the Chinese Academy of Sciences (Grant No. XDA21070302).

Conflicts of Interest: The authors declare no conflict of interest. 


\section{References}

1. Shchukina, E.M.; Graham, M.; Zheng, Z.; Shchukin, D.G. Nanoencapsulation of phase change materials for advanced thermal energy storage systems. Chem. Soc. Rev. 2018, 47, 4156-4175. [CrossRef]

2. Zalba, B.; Marín, J.M.A.; Cabeza, L.F.; Mehling, H. Review on thermal energy storage with phase change: materials, heat transfer analysis and applications. Appl. Therm. Eng. 2003, 23, 251-283. [CrossRef]

3. Lin, Y.; Jia, Y.; Alva, G.; Fang, G. Review on thermal conductivity enhancement, thermal properties and applications of phase change materials in thermal energy storage. Renew. Sustain. Energy Rev. 2018, 82, 2730-2742. [CrossRef]

4. Pandey, A.K.; Hossain, M.S.; Tyagi, V.V.; Abd Rahim, N.; Selvaraj, J.A.L.; Sari, A. Novel approaches and recent developments on potential applications of phase change materials in solar energy. Renew. Sustain. Energy Rev. 2018, 82, 281-323. [CrossRef]

5. Zhang, Y.; Li, X.; Li, J.; Ma, C.; Guo, L.; Meng, X. Solar-driven phase change microencapsulation with efficient $\mathrm{Ti}_{4} \mathrm{O}_{7}$ nanoconverter for latent heat storage. Nano Energy 2018, 53, 579-586. [CrossRef]

6. Hohlein, S.; Konig-Haagen, A.; Bruggemann, D. Thermophysical characterization of $\mathrm{MgCl}_{2} \cdot 6 \mathrm{H}_{2} \mathrm{O}$, xylitol and erythritol as phase change materials (PCM) for latent heat thermal energy storage (LHTES). Materials 2017, 10, 444. [CrossRef] [PubMed]

7. Miró, L.; Gasia, J.; Cabeza, L.F. Thermal energy storage (TES) for industrial waste heat (IWH) recovery: A review. Appl. Energy 2016, 179, 284-301. [CrossRef]

8. Xu, H.; Romagnoli, A.; Sze, J.Y.; Py, X. Application of material assessment methodology in latent heat thermal energy storage for waste heat recovery. Appl. Energy 2017, 187, 281-290. [CrossRef]

9. Qian, Z.; Shen, H.; Fang, X.; Fan, L.; Zhao, N.; Xu, J. Phase change materials of paraffin in h-BN porous scaffolds with enhanced thermal conductivity and form stability. Energy Build. 2018, 158, 1184-1188. [CrossRef]

10. Jin, X.; Zhang, S.; Xu, X.; Zhang, X. Effects of PCM state on its phase change performance and the thermal performance of building walls. Build Env. 2014, 81, 334-339. [CrossRef]

11. Fang, Y.; Ding, Y.; Tang, Y.; Liang, X.; Jin, C.; Wang, S.; Gao, X.; Zhang, Z. Thermal properties enhancement and application of a novel sodium acetate trihydrate-formamide/expanded graphite shape-stabilized composite phase change material for electric radiant floor heating. Appl. Therm. Eng. 2019, 150, 1177-1185. [CrossRef]

12. Wang, H.; Guo, L.; Liu, K.; Song, Z.; Wu, L.; Fang, M.; Li, J. Investigation of magnesium nitrate hexahydrate based phase change materials containing nanoparticles for thermal energy storage. Mater. Res. Express 2019, 6, 105512. [CrossRef]

13. Ma, Z.; Bao, H.; Roskilly, A.P. Study on solidification process of sodium acetate trihydrate for seasonal solar thermal energy storage. Sol. Energy Mater. Sol. Cells 2017, 172, 99-107. [CrossRef]

14. Dannemand, M.; Johansen, J.B.; Furbo, S. Solidification behavior and thermal conductivity of bulk sodium acetate trihydrate composites with thickening agents and graphite. Sol. Energy Mater. Sol. Cells 2016, 145, 287-295. [CrossRef]

15. Stritih, U.; Charvat, P.; Koželj, R.; Klimes, L.; Osterman, E.; Ostry, M.; Butala, V. PCM thermal energy storage in solar heating of ventilation air-Experimental and numerical investigations. Sustain. Cities. Soc 2018, 37, 104-115. [CrossRef]

16. Kenisarin, M.; Mahkamov, K. Salt hydrates as latent heat storage materials: Thermophysical properties and costs. Sol. Energy Mater. Sol. Cells 2016, 145, 255-286. [CrossRef]

17. Wang, H.; Chen, Y.; Li, J.; Guo, L.; Fang, M. Review of encapsulated salt hydrate core-shell phase change materials. Kona. Powder. Part. J 2020, 1, 2020010. [CrossRef]

18. Jin, X.; Zhang, S.; Medina, M.A.; Zhang, X. Experimental study of the cooling process of partially-melted sodium acetate trihydrate. Energy Build. 2014, 76, 654-660. [CrossRef]

19. Zhou, D.; Zhao, C.Y.; Tian, Y. Review on thermal energy storage with phase change materials (PCMs) in building applications. Appl. Energy 2012, 92, 593-605. [CrossRef]

20. Pielichowska, K.; Pielichowski, K. Phase change materials for thermal energy storage. Prog. Mater. Sci 2014, 65, 67-123. [CrossRef]

21. Beaupere, N.; Soupremanien, U.; Zalewski, L. Nucleation triggering methods in supercooled phase change materials (PCM), a review. Thermochim. Acta 2018, 670, 184-201. [CrossRef] 
22. Jin, X.; Medina, M.A.; Zhang, X.; Zhang, S. Phase-change characteristic analysis of partially melted sodium acetate trihydrate using DSC. Int. J. 2014, 35, 45-52. [CrossRef]

23. Hu, P.; Lu, D.-J.; Fan, X.-Y.; Zhou, X.; Chen, Z.-S. Phase change performance of sodium acetate trihydrate with AlN nanoparticles and CMC. Sol. Energy Mater. Sol. Cells 2011, 95, 2645-2649. [CrossRef]

24. Mao, J.; Dong, X.; Hou, P.; Lian, H. Preparation research of novel composite phase change materials based on sodium acetate trihydrate. Appl. Therm. Eng. 2017, 118, 817-825. [CrossRef]

25. Garay Ramirez, B.M.L.; Glorieux, C.; San Martin Martinez, E.; Flores Cuautle, J.J.A. Tuning of thermal properties of sodium acetate trihydrate by blending with polymer and silver nanoparticles. Appl. Therm. Eng. 2014, 62, 838-844. [CrossRef]

26. Cui, W.; Yuan, Y.; Sun, L.; Cao, X.; Yang, X. Experimental studies on the supercooling and melting/freezing characteristics of nano-copper/sodium acetate trihydrate composite phase change materials. Renew. Energy 2016, 99, 1029-1037. [CrossRef]

27. He, Y.; Zhang, N.; Yuan, Y.; Cao, X.; Sun, L.; Song, Y. Improvement of supercooling and thermal conductivity of the sodium acetate trihydrate for thermal energy storage with $\alpha-\mathrm{Fe}_{2} \mathrm{O}_{3}$ as addictive. J. Therm. Anal. Calorim 2018, 133, 859-867. [CrossRef]

28. Kong, W.; Dannemand, M.; Johansen, J.B.; Fan, J.; Dragsted, J.; Englmair, G.; Furbo, S. Experimental investigations on heat content of supercooled sodium acetate trihydrate by a simple heat loss method. Sol. Energy 2016, 139, 249-257. [CrossRef]

29. Cabeza, L.F.; Svensson, G.; Hiebler, S.; Mehling, H. Thermal performance of sodium acetate trihydrate thickened with different materials as phase change energy storage material. Appl. Therm. Eng. 2003, 23, 1697-1704. [CrossRef]

30. Ryu, H.W.; Woo, S.W.; Shin, B.C.; Kim, S.D. Prevention of supercooling and stabilization of inorganic salt hydrates as latent heat storage materials. Sol. Energy Mater. Sol. Cells 1992, 27, 161-172. [CrossRef]

31. Dannemand, M.; Dragsted, J.; Fan, J.; Johansen, J.B.; Kong, W.; Furbo, S. Experimental investigations on prototype heat storage units utilizing stable supercooling of sodium acetate trihydrate mixtures. Appl. Energy 2016, 169, 72-80. [CrossRef]

32. Li, X.; Zhou, Y.; Nian, H.; Zhang, X.; Dong, O.; Ren, X.; Zeng, J.; Hai, C.; Shen, Y. Advanced nanocomposite phase change material based on calcium chloride hexahydrate with aluminum oxide nanoparticles for thermal energy storage. Energy Fuel 2017, 31, 6560-6567. [CrossRef]

33. Ghule, A.; Bhongale, C.; Chang, $\mathrm{H}$. Monitoring dehydration and condensation processes of $\mathrm{Na}_{2} \mathrm{HPO}_{4} \cdot 12 \mathrm{H}_{2} \mathrm{O}$ using thermo-Raman spectroscopy. Spectrochim. Acta. A 2003, 59, 1529-1539. [CrossRef]

34. Huang, J.; Wang, T.; Zhu, P.; Xiao, J. Preparation, characterization, and thermal properties of the microencapsulation of a hydrated salt as phase change energy storage materials. Thermochim. Acta 2013, 557, 1-6. [CrossRef]

35. Calbo, L.J. Comprehensive Collection of Coating Additives; Shanghai Science and Technology Academic Press: Shanghai, China, 2000; pp. 336-338.

(C) 2020 by the authors. Licensee MDPI, Basel, Switzerland. This article is an open access article distributed under the terms and conditions of the Creative Commons Attribution (CC BY) license (http://creativecommons.org/licenses/by/4.0/). 